\title{
UPAYA PELAKSANAAN PERAWAT DALAM MENERAPKAN KESEHATAN DAN KESELAMATAN KERJA DI RUMAH SAKIT
}

\author{
Muhammad Anggi Ardiansyah
}

Anggi.ayeee@gmail.com

\section{Latar Belakang}

Kesehatan dan keselamatan kerja merupakan salah satu isu penting di dunia kerja saat ini. Keselamatan dan kesehatan kerja (K3) adalah suatu program yang dibuat pekerja maupun pengusaha sebagai upaya mencegah timbulnya kecelakaan akibat kerja dan penyakit serta tindakan antisipatif apabila terjadi kecelakaan dan penyakit kerja. Pengkajian ini di buat Untuk mengetahui upaya yang dapat dilakukan seorang perawat sebagai proteksi atau pelindung diri saat sedang bekerja. Metode yang saya lakukan menggunakan dalam kajian ini adalah dengan melakukan analisis data sekunder yaitu dengan kajian pustaka terhadap beberapa jurnal dan buku cetak yang berkenaan dengan kajian saya. Kesehatan dan keselamatan kerja merupakan salah satu isu penting di dunia kerja saat ini Di Indonsia, data dari Kementerian Kesehatan Republik Indonesia (2015) total kecelakaan kerja yang terjadi di Indonesia pada tahun 2014 sebanyak 24.910 kasus. Kecelakaan kerja menjadi salah satu masalah urgen di lingkungan rumah sakit. Hal ini diakibatkan karena rumah sakit merupakan suatu unit pelayanan kesehatan yang memberikan pelayanan pada semua bidang dan jenis penyakit. Oleh sebab itu rumah sakit dituntut untuk dapat menyediakan dan menerapkan suatu upaya agar semua sumber daya manusia yang ada di rumah sakit dapat terlindungi, baik dari penyakit maupun kecelakaan akibat kerja.

Dan untuk data mengenai Penyakit Akibat Kerja (PAK) dan Kecelakaan Kerja (KK) di sarana umum kesehatan secara umum belum tercatat dengan baik, namun menurut Departemen Kesehatan (Depkes) 2007, diketahui bahwa risiko bahaya yang dialami oleh pekerja di rumah sakit adalah infeksi HIV (0,3\%), risiko pajanan membrane mukosa (1\%), risiko pajanan kulit $(<1 \%)$ dan sisanya tertusuk jarum, terluka akibat pecahan gigi yang tajam dan bor metal ketika melakukan pembersihan gigi, low back paint akibat mengangkat beban melebihi batas, gangguan pernapasan, dermatitis danhepatitis. 
Kecelakaan kerja menjadi salah satu masalah urgen di lingkungan rumah sakit. Hal ini diakibatkan karena rumah sakit merupakan suatu unit pelayanan kesehatan yang memberikan pelayanan pada semua bidang dan jenis penyakit. Oleh sebab itu rumah sakit dituntut untuk dapat menyediakan dan menerapkan suatu upaya agar semua sumber daya manusia yang ada di rumah sakit dapat terlindungi, baik dari penyakit maupun kecelakaan akibat kerja Untuk mengetahui hal hal yang dapat dilakukan seorang perawat sebagai proteksi atau pelindung diri saat sedang bekerja.

\section{Metode}

Metode yang digunakan adalah teknik pengumpulan data atau informasi dengan melakukan analisis, eksplorasi, kajian bebas yang relevan yang berfokus pada pengetahuan keselamatan dan kesehatan kerja oleh perawat di Rumah Sakit dengan menggunakan 14 referensi, jurnal dan ebook.

\section{Hasil}

Berdasarkan hasil pencarian yang didapat bahwa Komite Keselamatan dan Kesehatan Kerja Rumah Sakit (K3RS) menyatakan cara meningkatkan pengetahuan perawat mengenai Keselamatan dan Kesehatan Kerja (K3) melalui sosialisasi, pelatihan K3, rapat internal ruangan perawatan berkala sebelum bekerja diharapkan timbul peningkatan sikap positif perawat tentang K3 serta timbul kesadaran pribadi dan membudayakan K3. Perawat mampu menerapakan K3 dengan baik dan benar untuk mengurangi terjadinya kecelakaan atau resiko bahaya yang dapat membahayakan perawat di rumah sakit. Pada literature review didapatkan hasil bahwa untuk meningkatkan kualitas kerja dan kepuasan pasien terhadap pelayanan kesehatan di rumah sakit, seorang perawat harus mampu memahami aspek-aspek dalam penerapan keselamatan pasien. Perawat wajib mengetahui tentang fungsi dan peran seorang perawat dan disarankan bekerja dengan memperhatikan fungsi dan perannya tersebut. Kesehatan dan keselamatan kerja sangat

penting diterapkan oleh perawat karena jika terjadi sesuatu akan menimbulkan kerugian ekonomi yang tentunya tidak diinginkan. Pentingnya kebijakan perawat dalam penerapan K3 yang nantinya dapat meningkatkan mutu pelayanan kesehatan. Reputasi perusahaan adalah modal pokok yang mencerminkan pada kemampuan perusahaan untuk memuaskan pelayanan kesehatan. 
Upaya ini meliputi peningkatan, pencegahan, pengobatan dan pemulihan. Kinerja setiap petugas kesehatan dan nonkesehatan merupakan resultante dari tiga komponen K3 yaitu kapasitas kerja, beban kerja dan lingkungan kerja. Komitmen dan Kebijakan Komitmen diwujudkan dalam bentuk kebijakan (policy) tertulis, jelas dan mudah dimengerti serta diketahui oleh seluruh karyawan RS. Manajemen RS mengidentifikasi dan menyediakan semua sumber daya esensial seperti pendanaan, tenaga K3 dan sarana untuk terlaksananya program K3 di RS.

\section{Pembahasan}

K3RS (Keselamatan dan Kesehatan Kerja Rumah Sakit) adalah segala kegiatan untuk menjamin dan melindungi keselamatan dan kesehatan bagi sumber daya manusia rumah sakit, pasien, pendamping pasien, pengunjung, maupun lingkungan rumah sakit melalui upaya pencegahan kecelakan kerja dan penyakit akibat kerja di rumah sakit. Pengertian tersebut merupakan pengertian yang ada pada Peraturan Menteri Kesehatan Nomor 66 Tahun 2016 tentang Keselamatan dan Kesehatan Kerja Rumah Sakit. K3RS sangat perlu untuk dilaksanakan karena banyaknya risiko yang dialami oleh tenaga medis di fasilitas rumah sakit. Selain itu, K3RS juga disyaratkan oleh regulasi-regulasi di Republik Indonesia. Tujuan K3RS (Keselamatan dan kesehatan kerja rumah sakit)

> Berdasarkan Permenkes nomor 66 tahun 2016 tentang Keselamatan dan Kesehatan Kerja Rumah Sakit, beberapa tujuan dalam pelaksanaan K3RS dapat dirangkum:

$>\quad$ Keselamatan dan keamanan di Rumah Sakit bertujuan untuk mencegah terjadinya kecelakaan. • Manajemen risiko K3RS bertujuan untuk meminimalkan risiko keselamatan dan kesehatan di Rumah Sakit sehingga tidak menimbulkan efek buruk terhadap keselamatan dan kesehatan SDM Rumah Sakit, pasien, pendamping pasien, dan pengunjung

$>\quad$. Pengaturan K3RS bertujuan untuk terselenggaranya keselamatan dan Kesehatan Kerja di Rumah Sakit secara optimal, efektif, efisien dan berkesinambungan.

$>\quad$ Pengelolaan Bahan Berbahaya dan Beracun (B3) dari aspek keselamatan dan Kesehatan Kerja Rumah Sakit bertujuan untuk melindungi sumber daya manusia Rumah Sakit, pasien, pendamping pasien, pengunjung, maupun lingkungan Rumah Sakit dari pajanan dan limbah Bahan Berbahaya dan Beracun (B3). 
Pencegahan dan pengendalian kebakaran bertujuan untuk memastikan SDM Rumah Sakit, pasien, pendamping pasien, pengunjung, dan aset Rumah Sakit aman dari bahaya api, asap, dan bahaya lain.

Pengelolaan prasarana Rumah Sakit dari aspek keselamatan dan Kesehatan Kerja bertujuan untuk menciptakan lingkungan kerja yang aman dengan memastikan kehandalan sistem utilitas dan meminimalisasi risiko yang mungkin terjadi.

$>\quad$ Pengelolaan peralatan medis dari aspek keselamatan dan Kesehatan Kerja Rumah Sakit bertujuan untuk melindungi SDM Rumah Sakit, pasien, pendamping pasien, pengunjung, maupun lingkungan Rumah Sakit dari potensi bahaya peralatan medis baik saat digunakan maupun saat tidak digunakan.

$>\quad$ Kesiapsiagaan menghadapi kondisi darurat atau bencana bertujuan untuk meminimalkan dampak terjadinya kejadian akibat kondisi darurat dan bencana yang dapat menimbulkan kerugian fisik, material, dan jiwa, mengganggu operasional, serta menyebabkan kerusakan lingkungan, atau mengancam finansial dan citra Rumah Sakit.

> Unit Pelayanan Kesehatan Kerja Rumah Sakit bertujuan untuk menurunkan kejadian dan prevalensi penyakit pada SDM Rumah Sakit dari penyakit menular, penyakit tidak menular, penyakit akibat kerja, dan kecelakaan akibat kerja. Sistem Keselamatan dan Kesehatan Kerja Rumah Sakit Sistem Keselamatan dan Kesehatan Kerja Rumah Sakit (SM K3RS) meliputi 5 hal berdasarkan Peraturan Menteri Kesehatan Nomor 66 Tahun 2016:

1. penetapan kebijakan K3RS;

2. perencanaan K3RS;

3. pelaksanaan rencana $\mathrm{K} 3 \mathrm{RS}$;

4. pemantauan dan evaluasi kinerja K3RS; dan

5. peninjauan dan peningkatan kinerja K3RS.

Kebijakan K3RS Kebijakan K3RS ditetapkan secara tertulis dengan Keputusan Kepala atau Direktur Rumah Sakit dan disosialisasikan ke seluruh SDM Rumah Sakit. Kebijakan K3RS meliputi: Penetapan kebijakan dan tujuan dari program K3RS: Kebijakan dan tujuan K3RS ditetapkan oleh pimpinan tertinggi Rumah Sakit dan dituangkan secara resmi dan tertulis. Kebijakan tersebut harus jelas dan mudah dimengerti serta diketahui oleh seluruh SDM Rumah Sakit baik manajemen, karyawan, kontraktor, pemasok dan pasien, pengunjung, pengantar pasien, tamu serta pihak lain yang terkait dengan tata cara yang tepat. Selain itu semuanya 
bertanggung jawab mendukung dan menerapkan kebijakan pelaksanaan K3RS tersebut, serta prosedur-prosedur yang berlaku di Rumah Sakit selama berada di lingkungan Rumah Sakit. Kebijakan K3RS harus disosialisasikan dengan berbagai upaya pada saat rapat pimpinan, rapat koordinasi, rapat lainnya, spanduk, banner, poster, audiovisual, dan lain-lain. Penetapan organisasi K3RS dantujuan dari program K3RS Dalam pelaksanaan K3 Rumah Sakit memerlukan organisasi yang dapat menyelenggarakan program K3RS secara menyeluruh dan berada di bawah pimpinan Rumah Sakit yang dapat menentukan kebijakan Rumah Sakit. Semakin tinggi kelas Rumah Sakit umumnya memiliki tingkat risiko keselamatan dan Kesehatan Kerja yang lebih besar karena semakin banyak pelayanan, sarana, prasarana dan teknologi serta semakin banyak keterlibatan manusia di dalamnya (sumber daya manusia Rumah Sakit, pasien, pengunjung, pengantar, kontraktor, dan lain sebagainya). Untuk terselenggaranya K3RS secara optimal, efektif, efesien dan berkesinambungan, Rumah Sakit membentuk atau menunjuk satu unit kerja fungsional yang mempunyai tanggung jawab menyelenggarakan K3RS. Unit kerja fungsional dapat berbentuk komite tersendiri atau terintegrasi dengan komite lainnya, dan/atau instalasi K3RS. Kebutuhan untuk membentuk unit kerja fungsional tersebut disesuaikan dengan besarnya tingkat risiko keselamatan dan Kesehatan Kerja, sehingga pada Rumah Sakit dapat memiliki komite atau instalasi K3RS, atau memiliki keduanya. Penetapan dukungan pendanaan, sarana, dan prasarana. Dalam pelaksanaan K3RS diperlukan alokasi anggaran yang memadai dan sarana prasarana lainnya. Hal ini merupakan bagian dari komitmen pimpinan Rumah Sakit. Perencanaan K3RS Rumah Sakit harus membuat perencanaan K3RS yang efektif agar tercapai keberhasilan penyelenggaraan K3RS dengan sasaran yang jelas dan dapat diukur. Perencanaan K3RS dilakukan untuk menghasilkan perencanaan strategi K3RS, yang diselaraskan dengan lingkup manajemen Rumah Sakit. Perencanaan K3RS tersebut disusun dan ditetapkan oleh pimpinan Rumah Sakit dengan mengacu pada kebijakan pelaksanaan K3RS yang telah ditetapkan dan selanjutnya diterapkan dalam rangka mengendalikan potensi bahaya dan risiko K3RS yang telah teridentifikasi dan berhubungan dengan operasional Rumah Sakit. Dalam rangka perencanaan K3RS perlu mempertimbangkan peraturan perundangundangan, kondisi yang ada serta hasil identifikasi potensi bahaya keselamatan dan Kesehatan Kerja. Pelaksanaan Rencana K3RS Program K3RS dilaksanakan berdasarkan rencana yang telah ditetapkan dan merupakan bagian pengendalian risiko keselamatan dan Kesehatan Kerja. Adapun pelaksanaan K3RS meliputi: 
1. Manajemen risiko K3RS;

2. Keselamatan dan keamanan di Rumah Sakit;

3. Pelayanan Kesehatan Kerja;

4. Pengelolaan Bahan Berbahaya dan Beracun (B3) dari Aspek keselamatan dan Kesehatan Kerja;

5. Pencegahan dan pengendalian kebakaran;

6. Pengelolaan prasarana Rumah Sakit dari Aspek keselamatan dan Kesehatan Kerja;

7. Pengelolaan peralatan medis dari Aspek keselamatan dan Kesehatan Kerja; dan

8. Kesiapsiagaan menghadapi kondisi darurat atau bencana. Pelaksanaan K3RS tersebut harus sesuai dengan standar K3RS. Susunan / Organisasi K3-RS Susunan Unit K3-RS terdiri dari :

$>\quad$ Bidang I : Bidang pengamanan peralatan medik, pengamanan radiasi dan limbah radioaktif

$>\quad$ Bidang II : Bidang pengamanan peralatan nonmedik, pengamanan dan keselamatan bangunan

$>\quad$ Bidang III : Bidang pengembangan sanitasi sarana kesehatan

$>\quad$ Bidang IV : Bidang pelayanan kesehatan kerja dan pencegahan penyakit akibat kerja

$>\quad$ Bidang V : Bidang pencegahan dan penanggulangan bencana Tugas Unit Organisasi K3-

RS

$>\quad$ Memberi rekomendasi dan pertimbanagan kepada Direktur RS tentang masalah-masalah yang berkaitan dengan K3_RS, Membuat program K3-RS, Melaksanakan program K3_RS, Melakukan evaluasi program K3-RS 2.

Tahap Pelaksanaan Program K3-RS

1. Pelaksanaan kesehatan kerja bagi karyawanb ( prakerja, berkala, khusus ).

2. Upaya pengamanan pasien, pengunjung dan petugas.

3. Peningkatan kesehatan lingkungan.

4. Sanitasi lingkungan RS.

5. Pengelolaan dan pengolahan limbah padat, cair, gas.

6. Pencegahan dan penanggulangan bencana (Disaster program). 
7. Pengelolaan jasa, bahan dan barang berbahaya.

8. Pendidikan dan pelatihan K3.

9. Sertifikasi dan kalibrasi sarana, prasarana, dan peralatan RS.

10. Pengumpulan, pengolahan dan pelaporan K3 Tahap Pemantauan dan Evaluasi 1. Inspeksi dan audit program K3.(2).Perbaikan dan pengendalian K3 yang didasarkan atas hasil temuan dari audit dan inspeksi. (3). Rekomendasi dan tindak lanjut hasil evaluasi program K3

\section{Penutup}

Seorang tenaga kesehatan atau perawat harus mengetahui tiga komponen K3 yaitu kapasitas kerja, beban kerja dan lingkungan kerja. Dan seorang perawat juga harus mengetahui Komitmen dan Kebijakan Komitmen diwujudkan dalam bentuk kebijakan (policy) tertulis, jelas dan mudah dimengerti serta diketahui oleh seluruh karyawan RS, agar tenaga kesehatan khususnya perawat terhindar dari risiko bahaya kerja di rumah sakit.

\section{Daftar Pustaka}

Arruum,D.,Salbiah.,Manik,M. (2015).Pengetahuan Tenaga Kesehatan Dalam Sasaran Keselamatan Pasien Di Rumah Sakit Universitas Sumatera Utara: Idea Nursing Journal.6,(2):14.

Bawelle, S.C. (2013). Hubungan pengetahuan dan sikap perawat dengan pelaksanaan keselamatan pasien (patient safety) di ruang rawat inap RSUD liun kendage tahune. E-journal Keperawatan. 1(1), 1-7.

Cahyono A. Hubungan karakteristik dan tingkat pengetahuan perawat terhadap pengelolaan keselamatan pasien di rumah sakit. 2015;3

Hakim,L.,Pudjirahardjo,W.J. (2014).Optimalisasi Proses Koordinasi Program Keselamatan Pasien (Patient Safety) Di Rumah Sakit X Surabaya. Jurnal Administrasi Kesehatan

Indonesia.2,(3):199-208.

Indrayani, P. (2016). Penerapan safety inspection sebagai upaya pencegahan kecelakaan kerja di PT. Multimas nabati asahan kuala tanjung tahun 2016 (Skripsi, Universitas Sumatera Utara). 
Muliawan, P. Dwiari, K. E. (2019). Faktor yang Berhubungan Dengan Pelaksanaan Keselamatan dan Kesehatan Kerja di Rumah Sakit Umum, Kota Denpasar. Arc. Com. Health. 6(2):17-29. Nugroho,SriH.P.,Sujianto,U. (2014).Supervisi Kepala Ruang Model Proctor Untuk Meningkatkan Pelaksanaan Keselamatan Pasien. Jurnal Keperawatan Indonesia.20, (1):56-64

Putri,S., Santoso., Rahayu, E. P. (2018). Pelaksanaan keselamatan dan kesehatan kerja terhadap kejadian kecelakaan kerja perawat rumah sakit. Jurnal Endurance, 3(2), 271-277.

Porajow, M.C,.dkk. (2016). Analisis penerapan standar pelayanan kesehatan dan keselamatan kerja rumah sakit (K3RS) di RSUP ratatotok buyat ratatotok kabupaten minahasa tenggara. Jurnal fakultas kesehatan masyarakat universitas sam ratulangi, 1(7), 1-10.

Rahmawati,R..(2017). Gambaran penerapan program keselamatan dan kesehatan kerja rumah sakit (K3RS) pada perawa di RSUD Tugurejo semarang (skripsi, universitas diponegoro).

Simamora, R. H. (2020). Pelatihan Komunikasi Efektif untuk Meningkatkan Efikasi diri Perawat dalam Pelaksanaan Identifikasi Pasien. JURNAL ILMIAH KESEHATAN MASYARAKAT: Media Komunikasi Komunitas Kesehatan Masyarakat, 12(1), 49-54.

Simamora, R. H. (2011). ROLE CONFLICT OF NURSE RELATIONSHIP WITH PERFORMANCE IN THE EMERGENCY UNIT OF HOSPITALS RSD DR. SOEBANDI JEMBER. The Malaysian Journal of Nursing, 3(2), 23-32. 